\title{
THE FIGHT OVER FIZZ: SODA TAXES AS A MEANS OF CURBING CHILDHOOD OBESITY?
}

\author{
Laura Hoffman, Esquire*
}

Childhood obesity is not just a health or family issue alone. It is an economic issue that impacts workforces, job growth, and local budgets across the country.

-White House Press Release, March 15, 2011 ${ }^{1}$

When Michelle Obama found her way to the White House as First Lady, she was a woman with a mission - to help children live healthier lives and tackle childhood obesity. In speaking of this endeavor, the First Lady stated: "In the end, as First Lady, this isn't just a policy issue for me. This is a passion. This is my mission. I am determined to work with folks across this country to change the way a generation of kids thinks about food and nutrition." 2 Mrs. Obama's dedication to this effort was not just talk. Her mission and passion led to the establishment of a federal campaign to fight childhood obesity and promote the education of children on health and nutrition known as Let's Move. ${ }^{3}$ Additionally, the First Lady's efforts have been supported by the actions of her husband, President Barack Obama. ${ }^{4}$ President Obama's commitment to this mission was first evidenced by his signature to the creation of the first ever federal Task Force on Childhood

\footnotetext{
* Laura C. Hoffman, Esq. is a candidate for a S.J.D. from Loyola University Chicago School of Law's Beazley Institute of Health Law and Policy. She earned an LL.M. in Child and Family Law from Loyola University Chicago School of Law in 2010. She holds a second LL.M. in Government and Law with a concentration in Civil and Constitutional Rights from American University Washington College of Law, '09. Laura earned her J.D. from Ave Maria School of Law in 2007. She holds a B.A. in Political Science, cum laude, from the University of Notre Dame, '04. She would like to thank her professional mentors, Professor Diane Geraghty, Professor John Blum, and Professor Michael Zimmer, for their continued support and encouragement of her legal scholarship and pursuit of a teaching career. Finally, she leaves a special thank you to her parents, Ronald and Janet Hoffman, and Robert L. Choromanski, Esq. for their gifts of unconditional love. She may be reached at lhoffman@luc.edu.

1. Press Release, The White House, Remarks by the First Lady at National League of Cities Conference (Mar. 15, 2011), available at http://www.whitehouse.gov/the-press-office/2011/03/15/remarksfirst-lady-national-league-cities-conference.

2. Press Release, The White House, Remarks by the First Lady at a Grocery Manufacturers Association Conference (Mar. 16, 2010), available at http://www.whitehouse.gov/the-press-office/remarksfirst-lady-a-grocery-manufacturers-association-conference.

3. Let's Move, http://www.letsmove.gov/about (last visited May 10, 2011).

4. Id.
} 
Obesity simultaneously with the development of the Let's Move campaign. ${ }^{5}$ Based on research done by this Task Force, it was recommended that Mrs. Obama's Let's Move campaign focused on the following four principles: 1. empowering parents and caregivers, 2. providing healthy food in schools, 3. improving access to healthy, affordable foods, and 4. increasing physical activity. ${ }^{6}$

However, creating and implementing legislative solutions to deal with the issues surrounding childhood obesity and nutrition have proved challenging. ${ }^{7}$ A major victory recently occurred at the federal level when President Obama signed the Healthy, Hungry-Free Kids Act of $2010^{8}$ that allows the federal government to address nutrition standards for foods in schools for the first time since the 1970s and allows regulation of events at school offering food options including bake sales. ${ }^{9}$ However, this legislation has caused some stir in the form of a debate over the extent of the role the government should have in these matters of food choices. ${ }^{10}$ In the year since the launch of the "Let's Move!" initiative, there is still doubt about whether or not it will be enough. ${ }^{11}$

This article aims to examine one of the recent attempts at curbing childhood obesity that has generated increasing attention and consideration as one available legislative solution, a tax on soda. ${ }^{12}$ While many states have tried to enact this type of legislation, several states that have been able to do

\section{Id.}

6. Id.

7. Press Release, Comm. on Educ. \& Labor, Innovative Approaches Needed to Combat Childhood
} Obesity, Witnesses Tell House Education Subcommittee (May 14, 2009), available at http://edworkforce .house.gov/News/DocumentSingle. aspx?DocumentID=173144.

8. Healthy, Hunger-Free Kids Act of 2010, S.3307, 111th Cong. (2010) (enacted), available at http://www.govtrack.us/congress/billtext.xpd?bill=s111-3307.

9. $\quad$ Press Release, White House, President Obama Signs Healthy, Hunger-Free Kids Act of 2010 Into Law (Dec. 13, 2010), available at http://www.whitehouse.gov/the-press-office/2010/12/13/presidentobama-signs-healthy-hunger-free-kids-act-2010-law; see also Obama Signs Child Nutrition Bill, CNN (Dec. 13, 2010), available at http://www.cnn.com/2010/POLITICS/12/13/child.nutrition/index.html; see also Landmark Child Nutrition Improvements to Become Law, CTR. FOR SCI. IN THE PUB. InTEREST (Dec. 2, 2010), available at http://www.cspinet.org/new/201012021.html.

10. Mary Clare Jalonick, Hold the Brownies! Bill Could Limit Bake Sales, Assoc. Press (updated Dec. 3, 2010), available at $\mathrm{http}: / / \mathrm{www} . \mathrm{msnbc} . \mathrm{msn} . \mathrm{com} / \mathrm{id} / 40497637 / \mathrm{ns} /$ health-diet_and_nutrition.

11. Jessica Pauline Ogilvie, Let's Move! Can It Make a Dent in the Childhood Obesity Problem?, L.A. Times (Mar. 20, 2011), available at http://articles.latimes.com/2011/mar/20/health/la-he-lets-moveassess-20110320.

12. Toni Okner, Soda Tax Ideas Grow Among Local Governments, TRIPLE Pundit (Mar. 8, 2010), available at http://www.triplepundit.com/2010/03/soda-tax/; see also Ginger Reilly, Illinois Groups Try To Solve Childhood Obesity, CHI. TRIBUNE (Dec. 15, 2010), available at http://articles.chicagotribune.com/ 2010-12-15/health/ct-x-s-health-obesity-summitt-1015-20101215_1_childhood-obesity-child-obesityobesity-rates. 
so have later had the laws repealed. ${ }^{13}$ Similarly, the federal government is rumored to be considering a tax of this nature. ${ }^{14}$ This article will begin by providing a basic introduction to childhood obesity. Next, this article will examine several different legislative responses that have been used at the federal and state levels to try to solve the dilemma of improving children's nutrition and combating childhood obesity. Then this article will closely examine the use of the soda tax as a particular legislative solution weighing both the pros and the cons of these taxes and providing some recent examples of these taxes and attempts to pass and implement them at the state level. Finally, I will offer the opinion that a soda tax may be successful addressing childhood obesity and even obesity in adults but 1) more evidence would be necessary to demonstrate the link between soda and obesity and 2) the soda tax alone cannot be expected or used to effectively combat childhood obesity.

\section{Introduction to Childhood Obesity}

According to the Centers for Disease Prevention and Control, "Obesity is a serious health concern for children and adolescents." 15 "More than 9 million U.S. children and youth are obese and another 15 percent are at risk for becoming obese." ${ }^{16}$ The prevalence of obesity among children and adolescents is seen as follows: "Childhood obesity has more than tripled in the past 30 years. The prevalence of obesity among children aged 6 to 11 years increased from $6.5 \%$ in 1980 to $19.6 \%$ in 2008 . The prevalence of obesity among adolescents aged 12 to 19 years increased from $5.0 \%$ to $18.1 \%$." ${ }^{17}$

13. Joey Peters, Soda Taxes Fizzle in Wake of Industry Lobbying, WASH. Post (July 13, 2010), available at $\mathrm{http}: / / \mathrm{www} . w a s h i n g t o n p o s t . c o m / w p-d y n / c o n t e n t / a r t i c l e / 2010 / 07 / 13 / A R 2010071303494 . h t m l ;$ see also Natalie Swaby, No More Candy Tax in Washington State, King5 News (Dec. 2, 2010), available at http://www.king5.com/news/No-More-Candy-Tax-111216009.html.

14. Obama Soda Tax 2009 Idea Gains Traction in 2010, Assoc. Content (Mar. 10, 2010), available at http://www.associatedcontent.com/article/2778658/obama_soda_tax_2009_idea_gains_ traction.html?cat $=5$.

15. Childhood Overweight \& Obesity, Ctrs. for Disease Control \& Prevention (updated Mar. 31, 2010), http://www.cdc.gov/obesity/childhood/index.html.

16. J. Michael McGinnis, et al., eds., Executive Summary: Food Marketing to Children \& Youth: Threat or Opportunity?, Nat'l Acad. of Scis., Comm. on Food Mktg. \& the Diets of Children (2006), available at http://static.publico.clix.pt/docs/pesoemedida/Iom_Food_Marketing_To_Children_Exec_ Summary_2006.pdf.

17. Div. of Adolescent \& Sch. Health, Nat'l Ctr. for Chronic Disease Prevention \& Health Promotion, Healthy Youth!, Ctrs. FOR Disease Control \& Prevention (last modified June 3, 2010), http://www.cdc.gov/healthyyouth/obesity. 
A child is initially screened for being overweight by the calculation of the child's Body Mass Index or "BMI." ${ }^{18}$ BMI involves a measurement to determine "weight status" by examining the relationship between a child's weight and height. ${ }^{19}$ While BMI is not an ultimate guarantee of measuring obesity, for it lacks precision in determining a child's body fat, it still is the most commonly accepted tool for first considering whether or not a child is overweight or obese. ${ }^{20}$ The definitions for "overweight" and "obese" are different and depend on an individual's BMI. ${ }^{21}$ "Overweight is defined as a BMI at or above the 85th percentile and lower than the 95th percentile. Obesity is defined as a BMI at or above the 95th percentile for children of the same age and sex." 22 Additionally, "weight status" determinations for children are further specialized by age and sex specific because children's weight patterns differ more according to these parameters than do adults. ${ }^{23}$ The distinctions between "overweight" and "obesity" for children and adolescents also take into consideration the age and sex of the child or adolescent because of differing body compositions as the child or adolescent becomes older which also differs by gender. ${ }^{24}$

Childhood obesity is generally understood to be the result of a child consuming more calories than the child burns off. ${ }^{25}$ More specifically, childhood obesity is explained as follows: "At the individual level, childhood obesity is the result of an imbalance between the calories a child consumes as food and beverages and the calories a child uses to support normal growth and development, metabolism, and physical activity. ${ }^{, 26}$ A number of factors, rather than a single factor, lead to obesity. ${ }^{27}$ These may include genetic, behavioral,

18. Div. of Nutrition, Physical Activity \& Obesity, Nat'l Ctr. for Chronic Disease Prevention \& Health Promotion, Basics about Childhood Obesity, Ctrs. For Disease Control \& Prevention (last updated Apr. 26, 2011), http://www.cdc.gov/obesity/childhood/basics.html.

19. Div. of Nutrition, supra note 18 ("A child's weight status is determined using an age- and sexspecific percentile for BMI rather than the BMI categories used for adults because children's body composition varies as they age and varies between boys and girls.").

20. Div. of Nutrition, supra note 18.

21. Id.

22. $I d$.

23. $I d$.

24. Id.

25. Div. of Nutrition, Physical Activity \& Obesity, Nat'l Ctr. for Chronic Disease Prevention \& Health Promotion, A Growing Problem, Ctrs. for Disease Control \& Prevention (last updated Apr. 21, 2011), http://www.cdc.gov/obesity/childhood/causes.html.

26. Ctrs. for Disease Control \& Prevention, Contributing Factors, eduCATIOn.com (last updated Oct. 20, 2009), http://www.education.com/reference/article/contributing-factors-obesity.

27. $I d$. 
and environmental factors. ${ }^{28}$ In considering genetic factors, the CDC stated: "Studies indicate that certain genetic characteristics may increase an individual's susceptibility to excess body weight." ${ }^{29}$ In some cases, genetic factors may need to combine with certain behavioral and environmental factors to lead to obesity. ${ }^{30}$ In other cases, genetics can be the sole cause of specific types of diseases linked to obesity. ${ }^{31}$

However, the recent growth in the instances of childhood obesity is less likely to be the result of solely genetics and more likely to be a combination of a number of different factors. ${ }^{32}$ The CDC has reflected this view that genetics cannot be the dominant factor leading to childhood obesity: "The genetic characteristics of the human population have not changed in the last three decades, but the prevalence of obesity has tripled among school-aged children during that time." ${ }^{33}$ Other factors that may influence obesity in children and adolescents are behavioral. ${ }^{34}$ Similar to genetics, because of the ability of a number of different behavioral factors to contribute to obesity in children, it is impossible to isolate one specific behavior as being a sole cause of obesity. ${ }^{35}$ Several behaviors are said to impact a child's "energy imbalance" that leads to obesity including energy intake, physical activity, and sedentary behavior. $^{36}$

While no specific foods have been linked to excessive energy intake, there are some eating habits that are acknowledged as contributing to the problem of energy intake in children. "[L]arge portion sizes for food and beverages, eating meals away from home, frequent snacking on energy-dense foods and consuming beverages with added sugar are often hypothesized as contributing to excess energy intake of children and teens." ${ }^{37}$ Another contributor to the energy intake problem is the consumption by children and adolescents of sugar sweetened drinks that often will result in higher calorie intake. $^{38}$

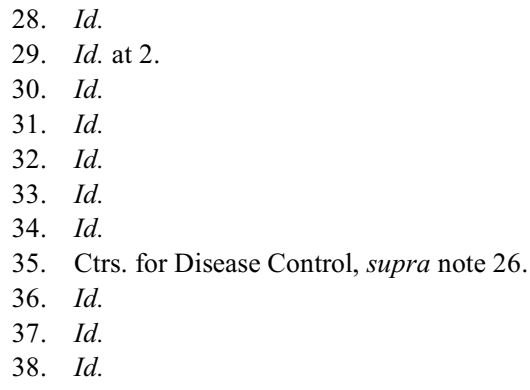


Physical activity can have a significant influence not only on a child's body weight but in providing additional benefits to the child's physical wellbeing. ${ }^{39}$ The sooner and more frequently physical activity is a part of a child's life, the more likely this activity will continue throughout the child's life. ${ }^{40}$ There has also been a substantial drop in the physical activity of children and adolescents in school:

Children may be spending less time engaged in physical activity during school. Daily participation in school physical education among adolescents dropped 14 percentage points over the last 13 years-from $42 \%$ in 1991 to $28 \%$ in 2003. In addition, less than one-third (28\%) of high school students meet currently recommended levels of physical activity. ${ }^{41}$

Sedentary behavior may also be tied to childhood obesity. "Children spend a considerable amount of time with media." ${ }^{43}$ There are numerous unhealthy habits that may develop from a child's excessive attention to the television that opens the door to negative health consequences because it can "displace time children spend in physical activities, contribute to increased energy consumption through excessive snacking and eating meals in front of the TV, influence children to make unhealthy food choices through exposure to food advertisements, and lower children's metabolic rate. ${ }^{\prime 4}$

Environmental factors may also influence childhood obesity. ${ }^{45}$ Several environments that may contribute to whether or not a child becomes obese include the child's home, child care, school, and community environments. ${ }^{46}$ These environments can affect both eating habits and the extent of physical activity a child engages in. ${ }^{47}$ In the home, the parent-child relationship can have a bearing on the eating behaviors of the child. ${ }^{48}$ "Parents are role models for their children who are likely to develop habits similar to their parents." 49 As more children spend time in child care, due to the demands of parents' careers, this environment is also a likely influence on a child. "Child care

40. Id.

41. Ctrs. for Disease Control, supra note 26.

42. $I d$.

43. $I d$.

44. Id.

45. $I d$.

46. Ctrs. for Disease Control, supra note 26 .

47. Id.

48. $I d$.

49. Id.

50. $I d$.
} 
can be a setting in which healthy eating and physical activity habits are developed." 51 The education environment plays a vital role in shaping a child's development in eating and physical activity: "Because the majority of young people aged 5-17 years are enrolled in schools and because of the amount of time that children spend at school each day, schools provide an ideal setting for teaching children and teens to adopt healthy eating and physical activity behaviors." 52 Finally, the community is an environmental factor that has a number of potential influences on the child. ${ }^{53}$ These include providing access to affordable and healthy food options and providing opportunities for physical activity that are also accessible. ${ }^{54}$

There are a number of health consequences that children may develop as a result of obesity. ${ }^{55}$ These health consequences may develop immediately for children and adolescents who become obese and others may develop into adulthood. ${ }^{56}$ One possible health consequence is the increased risk of cardiovascular diseases. ${ }^{57}$ "Obese children and teens have been found to have risk factors for cardiovascular disease (CVD), including high cholesterol levels, high blood pressure, and abnormal glucose tolerance." ${ }^{58}$ Additional health risks for children and adolescents who become obese that are less common include "asthma, hepatic steatosis, sleep apnea and Type 2 diabetes." ${ }^{59}$ Children and adolescents may also be exposed to the risk of psychosocial impact from obesity. ${ }^{60}$ Psychosocial risk may include the following: "Obese children and adolescents are targets of early and systematic social discrimination. The psychological stress of social stigmatization can cause low self-esteem which, in turn, can hinder academic and social functioning, and persist into adulthood." ${ }^{61}$ While the extent to which a child or adolescent may develop these health consequences as a result of obesity

51. Ctrs. for Disease Control, supra note 26.

52. Id.

53. $I d$.

54. Id.

55. Div. of Nutrition, Physical Activity \& Obesity, Nat'l Ctr. for Chronic Disease Prevention \& Health Promotion, Basics about Childhood Obesity, Ctrs. For Disease Control \& Prevention (last updated Apr. 26, 2011), available at $\mathrm{http} / /$ www.cdc.gov/healthy weight/children.

56. Div. of Nutrition, supra note 55.

57. $I d$.

58. Id.

59. $I d$.

60. $I d$.

61. $I d$. 
may differ, what remains consistent is the increased risk for developing adverse health consequences. ${ }^{62}$

\section{Avenues of Combating Childhood Obesity in Public Policy}

Various legislative efforts have been made in an attempt to curb childhood obesity in recent years at the federal, state, and local levels. "As obesity rates for both children and adults continue to climb, as well as obesityattributable medical expenditures, public health advocates search for effective prevention and intervention strategies. ${ }^{\circ 3}$ An overview of some of the areas that policy has been developed in to confront childhood obesity from different angles will help inform an evaluation of a recent legislative development and whether that will have any significant impact on childhood obesity in the near future.

\section{Food MARKETING to ChILDREN}

We have all seen those advertisements for food targeted at children complete with bright colors, flashy characters, and often the promise of extra goodies. Advertisements for foods are marketed to children in a number of media outlets:

Companies market food to children on television, on the radio, on the Internet, in magazines, through product placement in movies and video games, in schools, on product packages, as toys, on clothing and other merchandise, and almost anywhere where a logo or product image can be shown. ${ }^{64}$

Several methods are used by companies selling food products to lure children to wanting their products: "Food marketing techniques include the use of: spokes-characters, celebrities, cartoons, premiums, collectibles, games, contests, kids' clubs, and more." ${ }^{65}$ It is estimated that $\$ 10$ billion is spent annually by food companies in marketing their products to children. ${ }^{66}$ It should

62. Id.

63. Jamie F. Chriqui et al., State Sales Tax Rates for Soft Drinks and Snacks Sold through Grocery Stores and Vending Machines, 2007, 29 J. Pub. HeAlth \& PoL'y 226, 228 (2008) (only available at url by subscription)

64. Ctr. for Sci. in the Pub. Interest, Fact Sheet: Food Marketing to Children, http://www.cspinet .org/new/pdf/food_marketing_to_children.pdf (last visited May 20, 2011).

65. $I d$.

66. Id. 
not come as a surprise then that the coerciveness of these market strategies is thought to have a significant influence on contributing to a climate favorable for childhood obesity. "Creating an environment in which children and youth can grow up healthy should be a very high priority for the nation. Yet the prevailing pattern of food and beverage marketing to children in America represents, at best, a missed opportunity, and, at worst, a direct threat to the health of the next generation." ${ }^{67}$

Studies have shown that these marketing techniques have been effective

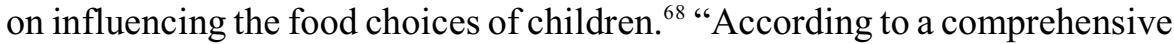
review in 2005 by the National Academies' Institute of Medicine, studies demonstrate that television food advertising affects children's food choices, food purchase requests, diets, and health." ${ }^{" 69}$ It has also been demonstrated that many children are too young to distinguish the reason for the advertisement. ${ }^{70}$ "Based on an extensive review of the research, the American Psychological Association concluded that until the age of about 8 years old children are unable to understand the persuasive intent of advertisements." "11 These advertisements would not be as much of a concern if they did not focus primarily on those very foods that have the greatest potential to lead children to become obese - fast foods and foods high in sugar, such as cereals. ${ }^{72}$ "About $80 \%$ of foods advertised on television shows intended for children are for convenience/fast foods and sweets." 73 These are likely to be foods that are high in calories, sodium, and sugar. ${ }^{74}$ "A 2000-calorie diet of advertised foods would exceed the USDA recommended guidelines for sodium and provide nearly 1 cup of added sugar." 75 The food advertisements have been fairly consistent over the past several years in the content of advertisements as evidenced by a study conducted by the Center for Science in the Public Interest (CSPI):

The total number of food ads during the 28 hours of television stayed fairly stable over the years, with 168 food ads in 2005 and 161 food ads in 2009. In 2005, the most frequently advertised foods were breakfast cereals ( $29 \%$ of food ads), fast-food and other restaurants $(19 \%)$, and pastries $(12 \%)$. In 2009 , the most frequently advertised foods

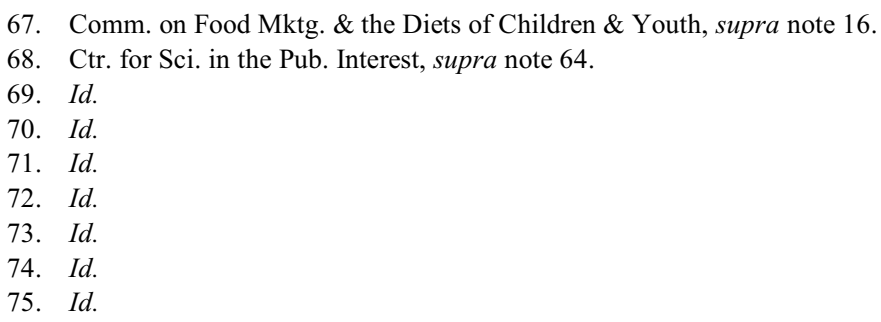


were fast-food and other restaurants (38\%), breakfast cereal (30\%), and yogurt (8\%). The proportion of ads for beverages increased from 1\% of all food ads in 2005 to $3 \%$ in 2009 . Brand ads, which focused on a brand with little or no depictions of food, also increased, from about $10 \%$ of food ads in 2005 to $27 \%$ in 2009 (mostly for fast food). ${ }^{76}$

There is concern that the food marketers undermine the authority of parents with their children by persuading children to want their products over healthful options parents may be promoting. " ${ }^{77}$ "Companies have resources to influence children's food choices that parents don't have, like cartoon characters, great music, celebrities, contests, and toy give-aways." ${ }^{.78}$

One policy approach towards reducing the effectiveness of these childcentric marketing campaigns conducted by fast-foods and other restaurant is mandated menu labeling and other regulations over unhealthy foods available when dining out. The evidence is clear that as more children dine out, the greater they are at risk of becoming obese from the unhealthy options being marketed towards them:

Kids are eating out more than ever before. Eating out accounts for one-third of children's daily calorie intake, twice the amount consumed away from home 30 years ago. Children consume almost twice as many calories when they eat a meal at a restaurant compared to a meal at home, and they get more saturated fat and less fiber and calcium than inhome cooked meals. ${ }^{79}$

One of the legislation initiatives to help kids cut down is to help educate parents and children by providing nutrition information on menus and menu boards at the point of ordering. "Six of the top 25 restaurant chains with children's menus provide no nutrition information at all. The chain restaurants that do provide nutrition information provide it in ways that are not easy for people to find and use when ordering in restaurants." "Some restaurants provide information on tray liners or fast food packages, like McDonald's does on the bottom of Happy Meal boxes. However, people don't see that

76. Center for Science in the Public Interest, Ameena Batada, Dr.P.H. \& Margo G. Wootan, D.Sc., Better-For-Who? Revisiting Company Promises on Food Marketing to Children, at 8, Nov. 2009, available at http://cspinet.org/new/pdf/pledgereport.pdf.

77. Ctr. for Sci. in the Pub. Interest, supra note 64.

78. Id.

79. Margo G. Wootan, Kids' Meals: Obesity on the Menu 1, Ctr. For SCI. In the Pub. Interest (Aug. 2008), http://cspinet.org/new/pdf/kidsmeals-report.pdf.

80. Menu Labeling, Ctr. FOR SCI. In the Pub. Interest, http://www.cspinet.org/menulabeling (last visited May 12, 2011).

81. Wootan, supra note 79 , at 9. 
information until after they order." ${ }^{\prime 2}$ Twenty states and localities are examining various forms of legislation to educate consumers that disclose nutritional information about the food they are eating when dining out. ${ }^{83}$ Five states - California, Oregon, Maine, New Jersey, and Massachusetts-have passed fairly extensive legislation or regulations on menu labeling. ${ }^{84}$ While at the federal level the Nutrition Label and Education Act of 1990 requires processed foods to have labels, the law provides an exemption for restaurants. ${ }^{85}$ With the passage of federal health care reform through the Patient Protection and Accountability Control Act (PPACA), restaurants across the nation will have to begin displaying calorie counts for regular menu items. ${ }^{86}$

In addition to making nutrition information more accessible, there have been other attempts to control marketing. San Francisco passed the "happy meal ban" and became the first city in the nation to pass legislation of this kind.$^{87}$ The ordinance prohibits including happy meal toys in any meals that exceed certain calorie levels. "Under the ordinance, scheduled to take effect in December 2011, restaurants may include a toy with a meal if the food and drink combined contain fewer than 600 calories, and if less than $35 \%$ of the calories come from fat." ${ }^{" 89}$ It also requires healthier food options including fruits and vegetables for meals that contain a toy. ${ }^{90} \mathrm{~A}$ similar ban has already been enacted in Santa Clara County in California. ${ }^{11}$ It is expected that the happy meal ban will spread across the country as a movement in due time. ${ }^{92}$ Most recently, a mother in Sacramento, California was joined by the Center for Science in the Public Interest (CSPI) in a class action lawsuit against McDonald's use of toys in happy meals claiming that these toys are used to

82. Id. at 11 .

83. Wootan, supra note 79 , at 9 .

84. Nutrition Labeling in Chain Restaurants: State and Local Laws/Bills/Regulations: 2009-2010 3-7, Ctr. FOr SCI. IN the Pub. Interest (Feb. 16, 2010), available at http://cspinet.org/new/pdf/ml_ bill_summaries_09.pdf.

85. Fact Sheet: Nutrition Labeling at Fast-Food and Other Chain Restaurants, CTR. FOR SCI. IN THE Pub. InTEREST (2008), available at http://cspinet.org/new/pdf/fact_sheet_2008.pdf.

86. Edward G. Grossman, Patient Protection and Affordable Care Act (PPACA) 518, available at http://docs.house.gov/energycommerce/ppacacon.pdf, also available at http://cspinet.org/new/pdf/ nationalmllaw.pdf.

87. Sharon Bernstein, San Francisco Bans Happy Meals, L.A. Times (Nov. 2, 2010), available at http://articles.latimes.com/2010/nov/02/business/la-fi-happy-meals-20101103.

88. $I d$.

89. $I d$.

90. Id.

91. Id.

92. Id. 
induce children to want the fast food causing the child's attention to be overwhelmed..$^{33}$

Some states have experimented with legislation that would impose additional taxes on soda or junk food more generally. ${ }^{94}$ "In 2008, states considered tax credits for fitness or wellness choices as well as the controversial approach of taxing foods and beverages with minimal nutritional value and, in a few states, directing the revenues to fund obesity or healthrelated services or programs." ${ }^{95}$ Another recent approach has been to bring litigation against companies for their marketing to children. ${ }^{96} \mathrm{~A}$ lawsuit aimed at Kellogg and Viacom's Nickelodeon is seeking to prevent them from continuing to market many foods with essentially no nutritional value to children:

The plaintiffs contend that these two companies are directly harming kids' health since the overwhelming majority of food products they market to children are high in sugar, saturated and trans fat, or salt, or almost devoid of nutrients. They will ask a Massachusetts court to enjoin the companies from marketing junk foods to audiences where 15 percent or more of the audience is under age eight, and to cease marketing junk foods through web sites, toy giveaways, contests, and other techniques aimed at that age group. ${ }^{97}$

These innovative efforts to control the marketing of food products to children are likely just the beginning in this area.

\section{Schools and the Availability of Low-Nutrition Foods}

One of the biggest avenues for fighting childhood obesity has been to target the availability of food products to children in schools that fall outside those provided through school meals. ${ }^{98}$ "Nationally, $83 \%$ of elementary schools, $97 \%$ of middle/junior high schools, and $99 \%$ of senior high schools sell foods and beverages out of vending machines, school stores, or a la carte

93. Class Action Lawsuit Targets McDonald's Use of Toys to Market to Children, CTR. FOR SCI. IN The Pub. InTERest (Dec. 15, 2010), available at http://www.cspinet.org/new/201012151.html.

94. Childhood Obesity-2008 Update of Legislative Policy Options, Nat'L Council of State Legislatures (Dec. 2008), available at http://www.ncsl.org/?tabid=13883.

95. Id.

96. Food Marketing Lawsuit against Nickelodeon \& Kellogg, Ctr. For SCI. IN the Pub. Int., available at $\mathrm{http}: / / w w w . c s p i n e t . o r g /$ nutritionpolicy/policy_options_marketinglawsuit.html.

97. Parents and Advocates Will Sue Viacom \& Kellogg, CTR. FOR SCI. In the Pub. Int. (Jan. 18, 2006), available at http://www.cspinet.org/new/200601181.html.

98. Improve School Foods: Background/Resources, available at http://www.schoolfoods.org/ resources.html (last visited May 12, 2011). 
in the cafeteria." ${ }^{" 99}$ There is concern that the availability of low-nutrition foods at schools as options for children will lead them to use money given to them for school lunches to choose instead from the unhealthy options available. ${ }^{100}$ "The sale of foods outside of the meal programs can negatively affect children's diets, since many are high in calories, added sugars, and fat and low in nutrients." 101 Consequently, numerous legislative efforts have been launched to try to prevent the availability of low-nutrition food and beverage options to children and adolescents at school.

The National Alliance for Nutrition and Activity has endorsed that the U.S. Department of Agriculture should be provided with the authority to reexamine the nutrition standards of foods sold at schools outside of the regular school meals. ${ }^{102}$ "Nutrition science has evolved since the U.S. Department of Agriculture implemented its nutrition standards in the 1970s. The current standards no longer make sense from the standpoint of nutrition science, current dietary patterns, and public health concerns." ${ }^{103}$ The current nutrition standard for foods sold outside of school meals still allows for the availability for unhealthy options for children and adolescents like French fries and cookies: "Current nutrition criteria for foods sold outside of meals apply only to foods of 'minimal nutritional value' that may not be in the foodservice area during meal time."

Among one of the greatest contributors to the availability of low-nutritional food options in schools has been the prevalence of vending machines. ${ }^{105}$ "Between 1991 and 2005 , the percentage of middle schools with vending machines increased from $42 \%$ to $82 \%$ and the percentage of high schools from $76 \%$ to $97 \%$." ${ }^{106}$ There is also evidence that there are not adequate policies in place to protect children against having access to these unhealthy options in schools. ${ }^{107}$ "Nationwide, only $30 \%$ of school districts prohibit the sale of junk foods in school vending machines. Two-thirds of states have weak or no nutrition standards for foods sold outside of meals." ${ }^{108}$ As the potential impact of having low-nutrition foods readily available at schools becomes increasingly manifest,

99. Improve School Foods, supra note 98.

100. $I d$.

101. Id.

102. Nat'l Acad. for Nutrition \& Activity, Update National School Nutrition Standards, available at $\mathrm{http}: / /$ cspinet.org/new/pdf/school_nutrition_standards_fact_sheet_2010.pdf.

103. Id.

104. Id.

105. Id.

106. Id.

107. Id.

108. Id. 
policymakers have begun taking serious steps to limit their availability to schoolchildren so as to reduce the increased risk of obesity such children face. ${ }^{109}$

At the state level, numerous pieces of legislation have been passed regarding school nutrition taking a variety of approaches. ${ }^{110}$ The most recent information on this legislation is available from the National Conference of State Legislatures (NCSL) for 2008. ${ }^{111}$ According to NCSL, "In 2008, at least 23 states considered some type of school nutrition legislation." 112 Six of these states - Colorado, Massachusetts, Michigan, New Hampshire, Tennessee and Virginia-enacted legislation designed to improve the quality of foods and beverages at schools that involved either "additional policies or studies." ${ }^{113}$ To illustrate the types of legislation enacted, Colorado's law establishes a prohibition on certain types of beverages and creates exceptions when prohibited beverages are allowed for specified school events. New Hampshire created a Commission on the Prevention of Childhood Obesity to examine and develop policies and strategies for combating childhood obesity which included the establishment of school nutrition standards. ${ }^{114}$ Some states have also considered legislation to limit or prohibit the availability of foods high in trans fat in schools. ${ }^{115}$ California, New Jersey, North Carolina, and Oregon enacted this type of legislation in 2007. ${ }^{116}$ In 2008, Tennessee also considered legislation to prohibit foods high in trans fat in schools but did not pass the legislation and Louisiana passed legislation that would enable the state to examine the feasibility of enacting such legislation. ${ }^{117}$

Another area that has become increasingly popular in battling childhood obesity has been to impose new laws regulating school vending machines. ${ }^{118}$ In 2003, Arkansas and California enacted legislation for the regulation of school vending machines. ${ }^{119}$ The Arkansas law prohibited access to vending

109. Nat'L Council of State Legislatures, supra note 94.

110. $I d$.

111. $I d$.

112. Id. (referencing Alabama, California, Colorado, Connecticut, Florida, Hawaii, Idaho, Iowa, Maine, Massachusetts, Michigan, Minnesota, Missouri, New Hampshire, New Jersey, New Mexico, North Carolina, Rhode Island, South Carolina, Tennessee, Virginia, Washington and West Virginia).

113. Id.

114. Id.

115. Nat'L Council of State Legislatures, supra note 94.

116. $I d$.

117. $I d$.

118. Vending Machines in Schools (2005), Nat'L Council of State Legislatures, available at http://www.ncsl.org/default.aspx?tabid=14108.

119. Id. 
machines containing junk foods and beverages to elementary school students. ${ }^{120}$ This was the first law in the nation to ban vending machines in elementary schools. ${ }^{121}$ California's law required the replacement of carbonated beverages in school vending machines with healthy beverage options including milk, water, and juice. ${ }^{122}$ The law also restricted the time of day during which students were able to access machines to only certain periods before and after school. ${ }^{123}$ Laws were passed in 2004 by Colorado, Louisiana, Tennessee, and Washington that required school districts and boards to develop policies regarding nutrition standards for foods available in schools. ${ }^{124}$ Many states also considered proposals involving school vending machines in $2005 .^{125}$

A more recent example comes out of a bill signed into law in Massachusetts in July 2010. ${ }^{126}$ Under this law, the state health board is provided regulatory authority to control what options are available in school vending machines. ${ }^{127} \mathrm{~A}$ similar policy was developed in Kansas requiring its schools to implement food and beverage guidelines created by the Kansas State Board of Education in May 2010. ${ }^{128}$ It is important to remember that policies regarding school vending machines may be developed at lower levels as well. "This is not just a state issue, however. Some cities and local schools districts have taken the lead and enacted policies to ban or replace certain foods and beverages in vending machines or restrict student access to the machines." 129

This emergent national trend of states creating legislation to regulate school vending machines largely came as a result of the current inadequacy of federal law to address the issue. However, a recent legislative development has changed this landscape. The recent passage of the Healthy, Hunger-Free Kids Act of 2010 will fill the gap that had been left open for some time at the federal level for regulation of food and beverage products available at schools

120. $I d$.

121. $I d$.

122. $I d$.

123. $I d$.

124. $I d$.

125. NAT'L Council of STAte Legislatures, supra note 118.

126. Adam Ragusea, School Vending Machines Will Be Regulated under New Bill, wBur.org (July 30, 2010), available at http://www.wbur.org/2010/07/30/healthy-school-food-bill.

127. Id.

128. School Vending Machine Requirement to Proceed, Kan. Health Inst. (updated July 14, 2010), available at $\mathrm{http}: / / \mathrm{www} . \mathrm{khi} .0 \mathrm{gg} / \mathrm{news} / 2010 / \mathrm{ju} / \mathrm{13} /$ school-board-hears-comments-vending-machine-policy/.

129. Nat'L Council of State Legislatures, supra note 118. 
outside of regular school meals. ${ }^{130}$ The significance of this bill to the regulation of school vending machines is as follows: "The bill requires the U.S. Department of Agriculture to update its nutrition standards for foods that can be sold through vending machines, a la carte lines, and elsewhere on school grounds. Current standards are 30 years out of date and apply only to the cafeteria during mealtimes." ${ }^{131}$ The bill even offers incentives for school districts to comply with the implementation of the new nutritional standards created by the U.S. Department of Agriculture by increasing the district's federal reimbursement rate by 6 cents per meal for schools that appropriately implement the standards. ${ }^{132}$ The law is seen by many as a major step in the fulfillment of a national effort against childhood obesity that was spearheaded by First Lady Michelle Obama. ${ }^{133}$

In January 2010, Mrs. Obama launched the national campaign against childhood obesity. ${ }^{134}$ The Healthy, Hunger Free-Kids Act of 2010 calls for the reauthorization of the Child Nutrition Act. ${ }^{135}$ "The Healthy, Hunger-Free Kids Act of 2010 would commit an additional $\$ 4.5$ billion to child-nutrition programs over the next 10 years and implement the most sweeping changes to those programs in decades." ${ }^{\text {136 }}$ A congressman speaking in support of the bill's passage described the interrelationship between a child's health, wellbeing and academic success as a key driving force in passing this legislation. ${ }^{137} \mathrm{He}$ also advocated for the bill's ability to combat two major problems facing children and nutrition: "Childhood hunger and poor nutrition are two of the greatest public health challenges - and education challenges - facing our country today." $" 138$ In attempting to combat child hunger, one of the bill's biggest components is the expansion of providing meals to children of low-income families:

130. Landmark Child Nutrition Improvements to Become Law, CTR. FOR SCI. IN THE PUb. INTEREST (Dec. 2, 2010), available at http://www.cspinet.org/new/201012021.html.

131. Id.

132. Peter Eisler, Sweeping School Lunch Bill Clears Senate Panel, USA Today (Mar. 25, 2010), available at http://www.usatoday.com/news/education/2010-03-24-school-lunch-safety_N.htm.

133. Brenda Wilson, Michelle Obama Launches Personal Campaign Against Childhood Obesity, NPR.ORG (Jan. 29, 2010), available at $\mathrm{http}: / /$ www.npr.org/blogs/health/2010/01/michelle_obama_launches_ person.html.

134. Wilson, supra note 133.

135. Healthy, Hunger-Free Kids Act, supra note 8.

136. Eisler, supra note 132.

137. 156 Cong. ReC. H7767-01 (daily ed. Dec. 1, 2010) (statement of Congressman Jared Polis), available at http://www.jaredpolis.house.gov/News/DocumentSingle.aspx?DocumentID=216513.

138. Id. 
One of the bill's chief goals is to expand the number of students eligible for free or reduced-price meals. For example, schools in high-poverty areas could deem all their students to be eligible, without having to show proof of family income. And all foster children would automatically be eligible for those meals. ${ }^{139}$

Another hallmark of the law is the inclusion of greater safety standards for school foods to prevent tainting and contamination. ${ }^{140}$

\section{Physical Activity, Recess, and Wellness}

A final area deserving of attention in efforts to respond to the childhood obesity epidemic involves legislative attempts to improve standards in schools for children involving physical education, recess, and wellness. "Forty-nine states require physical education in schools, but the scope of the requirement varies greatly." 141 In 2008, twenty-three states considered or enacted legislation or resolutions involving physical activity requirements for children in schools. ${ }^{142}$ Six states enacted legislation regarding physical activity in $2008{ }^{143}$ Several states also considered but did not enact legislation in 2008 involving physical education or physical activity. ${ }^{144}$ There have also been efforts to use legislation to increase the amount of physical activity that students participate in during the school day. ${ }^{145}$ Challenges are often raised to this type of legislation, fore example, that it detracts from time that is needed during the regular school day for education and that it is also a costly endeavor for schools. ${ }^{146}$ Greater acceptance has developed that an increase in physical activity leads to improvement in academics. ${ }^{147}$

However, requirements of physical education continue to be problematic as evidenced by a recent national trend regarding the ability of students to be exempt from physical education classes: "Despite growing concerns about obesity among young people, the number of states that allow students to waive

139. Eisler, supra note 132.

140. $I d$.

141. Nat'l Council of State Legislatures, supra note 94.

142. $I d$.

143. Id. (listing Colorado, Florida, Maryland, New Mexico, Oklahoma and Virginia).

144. Id. "'States that considered, but did not enact, new or additional legislation regarding physical education or physical activity in 2008 included Alabama, Arizona (governor vetoed a bill that would have prohibited eliminating physical education), California, Hawaii, Kansas, Kentucky, Massachusetts, Michigan, Minnesota, Mississippi, Missouri, New Jersey, New York, North Carolina, Ohio, Rhode Island and Washington.").

145. Id.

146. $I d$.

147. Nat'L Council of State Legislatures, supra note 94. 
or substitute physical education classes has grown from 27 to 32 since 2006, according to Paula Kun, a spokeswoman for the National Association for Sport and Physical Education (NASPE)." ${ }^{148}$ In these states, children are often allowed to use alternatives to fulfill physical education requirements from marching band to cheerleading. ${ }^{149}$ Another legislative approach used by some states has been to mandate recess time. ${ }^{150}$ "In 2008, state legislation regarding recess was enacted in Oklahoma and recess legislation or resolutions were considered in Missouri and New Jersey." "

Finally, more states have taken a broader and more comprehensive approach to facing childhood obesity by enacting or considering legislation to reform school wellness policies. ${ }^{152}$ "In 2008, statewide legislation in support of wellness policies or related school health efforts was enacted in Colorado and considered in at least 10 other states including Florida, Georgia, Kansas, Maryland, Massachusetts, Missouri, New York, Ohio, Virginia and Washington." 153 The development of wellness policies by states largely came as a response to the requirement of federal law for school districts to implement wellness policies. ${ }^{154}$

\section{Who Is Involved in the Childhood Obesity Debate?}

The development of any policies regarding childhood obesity will create a host of issues for various parties. First, the food industry itself including restaurants, food retailers, and manufacturers is certainly implicated in having to deal with changes in law that create regulations on them for things such as marketing and labeling to meet these standards. The food industry is a vital part of the nation's economy and there is the possibility that if these legislative endeavors involving marketing and labeling are as effective as the government

148. Grant Schulte \& Sheena Dooley, More States Let Students Opt Out of P.E. Classes, USA TodAY (updated Dec. 14, 2010), http://www.usatoday.com/news/education/2010-12-14-physed14_ST_N.htm? $\mathrm{POE}=$ click- refer.

149. Id.

150. Nat'L Council of State Legislatures, supra note 94.

151. $I d$.

152. $I d$.

153. $I d$.

154. Id. ("The federal Child Nutrition and WIC Reauthorization Act of 2004 (Public Law 108-265) required each local school district participating in the National School Lunch and/or Breakfast Program to establish a local wellness policy by the beginning of the 2006-2007 school year. School districts were required to involve a broad group of stakeholders in developing wellness policies and set goals for nutrition education, physical activity, campus food provision, and other school-based activities designed to promote student wellness. Plans for measuring policy implementation were required to be included."). 
hopes, the food industry will take a hit by the reduction of sales of food and beverage products. There is also the argument that the actors in the food industry should be able to market products as they desire. Should the food industry be subject to more rigorous standards than other industries? Where does or should the line fall between the food industry having the right to market its products and the intrusion on the industry by government regulation?

Next, there is the individual. The individual as a consumer has a right to know about the product being purchased - in this case, foods and beverages. The question that this creates is how much should the food industry be required to disclose about its food and beverage products. Regulation of food and beverage products at the federal level in terms of packaging are already subject to regulation but surely new and diverse types of regulation have the ability to complicate matters more for anyone involved in the food industry. There are also arguments in the case of children, that parents should have the authority to make decisions for their children about food and drink consumption rather than the government interfering by making those decisions.

Finally, there is society at large and what level of protection the government owes the public in ensuring that members of society are appropriately warned and protected against the negative health consequences evidenced by the consumption of food or drink products that are thought to contribute to obesity. The government is in the difficult position of attempting to balance a concern for the health of its citizens with to need to allow the food industry to thrive because of the food industry's value to the economy. There are no easy answers to weighing these interests in creating a regulatory framework, in particular, when people's good health may be at stake by the regular consumption of certain food and beverage products. In the cases of other legislation discussed that have to do with schools, the question often becomes what should the role of schools be in keeping children healthy. This again creates a question as to whether the school is inappropriately intervening into parental control and responsibility for raising children. Additionally, schools have the challenge of funding and how much time and resources can be spent on any health policy directed at children that involves a role by the schools. Issues of public health law involve the intersection of private industry, the individual, and community/society as a whole and we cannot ignore these unique relationships in the area of exploring policy options to confront the issue of childhood obesity. 


\section{The Fight Over Fizz: Soda Taxes Stir Controversy}

Among the latest controversies in the legislative efforts to confront obesity in both children and adults has been whether or not states should consider taxing soda. ${ }^{155}$ The Yale University Rudd Center for Food Policy and Obesity made the following observations regarding sugar-sweetened drinks and the risks posed to children and adults:

Sugar-sweetened beverages with little or no nutrition are staples of today's American diet. These beverages are inexpensive, in abundant supply, and appeal to our taste for sugar. They are heavily marketed, especially to children, often using celebrities, sports stars, and cartoon characters. More than for any category of foods, rigorous scientific studies have shown that consumption of soft drinks is associated with poor diet, increasing rates of obesity, and risk for diabetes. These links are strong for children. ${ }^{156}$

"A 2004 study found that soft drinks are the single largest contributor of calorie intake in the United States."157 The consumption of sweetened beverages by children cannot be ignored: "The percentage of beverage calories from sweetened beverages consumed by two 18-year-olds has increased, while the percentage from milk has decreased. In the mid-1990s the intake of sugared beverages began surpassing that of milk." 158 The daily intake of these sweetened beverages can significantly impact the chances of a child becoming obese. ${ }^{159}$ "For children, each extra can or glass of sugar-sweetened beverage consumed per day increases their chance of becoming obese by $60 \%$." 160

The federal government has even reported that taxing sweetened beverages could have a dramatic impact on improving the rate of obesity of both adults and children nationally. ${ }^{161}$ "Raising taxes to create a 20 percent increase in the price of sweetened beverages would lead to adults losing nearly

155. Trish Choate, Tobacco-Like Tax on Sodas Mulled, Times Record News (Nov. 11, 2010), available at http://www.timesrecordnews.com/news/2010/nov/11/tobacco-like-tax-on-sodas-mulled/? partner=yahoo_feeds.

156. Rudd Report: Soft Drink Taxes-A Policy Brief, Yale Univ. Rudd Ctr. For Food Policy \& OBEsITy (2009), available at http://www.yaleruddcenter.org/resources/upload/docs/what/reports/Rudd ReportSoftDrinkTaxFall2009.pdf.

157. Rudd Report, supra note 156.

158. Id.

159. Id.

160. Id.

161. Choate, supra note 155. 
4 pounds a year and children losing 4.5 pounds year, according to a U.S. Department of Agriculture study released in July." 162

The efforts to enact these types of taxes have increased on the state and local levels level: "Small excise taxes on soda are already in place in Arkansas, Tennessee, Virginia, Washington and West Virginia, and Chicago imposes a 3 percent retail tax on soft drinks. Soda taxes were proposed in at least 12 other states in 2009, though none were approved." ${ }^{\prime 163}$ But as much advocacy as there currently is for a soda tax, there is as much objection, even in addressing childhood obesity: "Even if soda consumption were to drop, say critics of the tax, a drop in childhood obesity isn't guaranteed." 164 The contentiousness of the debate over taxing soda can be seen in the State of Washington where a tax that passed into state law on soda was recently repealed in November by voter initiative. ${ }^{165}$ The State of Colorado is the most recent success in taxing both soda and candy although it comes largely due to the state's desperate need for funding as opposed to a specific attack targeting obesity. ${ }^{166}$ Colorado has yet to fall victim to the beverage industry that has lobbied hot and heavy against other states including Maine and Washington in repealing their taxes on soda. ${ }^{167}$

Despite the presence of such debates, Vermont recently proposed a similar tax where a proposed penny per ounce tax on sweetened drinks is causing quite a stir. ${ }^{168}$ However, unlike many other proposed soda taxes the Vermont plan distinguishes between sweetened and artificially sweetened beverages (i.e. Diet Coke, Diet Pepsi) by opting not to tax the later, claiming that there is no evidence linking obesity to artificially sweetened beverages. ${ }^{169}$ The latest passage of a soda tax in the State of Colorado will be examined in companion with a new attempt being launched in the State of Vermont to impose a soda tax serving as the basis for examining this debate.

162. $I d$.

163. Mark Bittman, Soda: A Sin We Sip Instead of Smoke?, N.Y. Times (Feb. 13, 2010), available at http://www.nytimes.com/2010/02/14/weekinreview/14bittman.html.

164. Bittman, supra note 163.

165. Peters, supra note 13; see also Swaby, supra note 13.

166. Steven K. Paulson, Colorado Governor Signs Bills to Tax Candy, Soda, Bloomberg BusinessWEeK (Feb. 25, 2010), available at http://www.businessweek.com/ap/financialnews/D9E37S900. htm.

167. Peters, supra note 13; Swaby, supra note 13.

168. Jennifer Reading, Proposed Soda Tax Sparks Controversy, WCAX News (Dec. 3, 2010), available at $\mathrm{http}: / /$ www.wcax.com/Global/story.asp?S=13614272.

169. Reading, supra note 168. 


\section{To TAX OR Not to TAx Soda?}

Several arguments have been raised in support of the use of taxing soda as a legislative policy approach to helping to fight obesity for both children and adults. One argument is made that the use of a similar "sin tax" on tobacco products has been successful in discouraging people from smoking as tobacco regulation has been a challenge for in the area of public health. ${ }^{170}$ "The success of tobacco excise taxes on reductions in tobacco consumption has often been used as an indicator for the success of imposing specific excise taxes on soft drinks and snacks." 171

Another argument favoring taxing soda and other junk food options is that these taxes would help eliminate the contribution of these items in causing obesity because their cheaper cost has contributed significantly to their widespread use. ${ }^{172}$ "A snack or soft drink tax could help narrow the gap between the disproportionate costs of healthy foods vs. non-healthy foods, no longer promoting non-healthy foods by means of being the 'cheapest choice' available." 173 This would ensure that people would not simply defer to nonhealthy foods because of the lower cost. Taxing a class of products such as sweetened beverages has the potential to raise revenue that could greatly contribute to a state collecting money that could be utilized to other efforts to battle obesity: "Taxing certain classes of products to reduce consumption has been proposed as one means of improving the nation's nutrition, raising revenue for health programs, and recovering costs caused by consumption of calorie-dense, nutrient-poor foods." subsidies for healthy foods and to create health programs for children at schools. ${ }^{175}$ Similar to arguments supporting menu labeling, advocates for taxes on sodas argue that when consumers demand healthier options, this can lead marketers to provide healthier options to meet the market's new demands. ${ }^{176}$

Taxing soda and other junk food is not favored by all. One of the arguments against this type of tax is the acknowledgment that while sugary drinks may contribute to obesity, like anything else, it is not the only factor-obesity is heavily influenced by the entire calorie intake of the

170. Chriqui et al., supra note 63, at 228.

171. $I d$.

172. $I d$

173. Id.

174. Rudd Report, supra note 156.

175. $I d$.

176. $I d$. 
individual and the physical activity that the individual participates in that determines the individual's energy use. ${ }^{177}$ A report by the U.S. Department of Health and Human Services on healthy weight stated:

A person's weight is the result of many things - height, genes, metabolism, behavior, and environment. Maintaining a healthy weight requires keeping a balance ... a balance of energy. You must balance the calories you get from food and beverages with the calories you use to keep your body going and physically active. ${ }^{178}$

Additionally, evidence has not established that consumption of calories by the sweet taste of soda has a direct link to obesity:

It turns out that there is practically no reliable scientific support for using soda taxes to fight obesity. That's clear from the research literature. It is easy to cite simultaneous upward trends in body weight and soda consumption, but the connection between the two is far from established. Instead of being a cause, extra soda consumption may be a result of ingesting more calories for reasons that have nothing to do with any particular beverage. Moreover, if a penny per ounce tax pushes soda consumption down, there's no guarantee that calories go down. That's partly because people tend to compensate, maybe by drinking an extra high-calorie fruit drink or two. This compensation phenomenon has cropped up over and over again when scholars track prices, taxes and consumption patterns through time. Even if a tax did cut out a 12-ounce sugar-sweetened beverage every day, the impact on total calories could be trivial. ${ }^{179}$

Even in light of the studies that have been done to examine if there was any connection between the consumption of soda beverages and obesity, the results have mirrored those of many in healthy policy. ${ }^{180}$ "In the case of diet and obesity, research based on correlations has provided contradictory evidence on the impact of soda prices or taxes; the most rigorous statistical studies tend to find no impact at all." ${ }^{181}$ A recent study included in the Archives of Internal Medicine noted that the average weight loss by the imposition of a soda tax would only be 1.3 pounds. ${ }^{182}$ Furthermore, the

177. John E. Calfee, Soda Tax: Will It Actually Help Reduce Obesity Rates?, Huffington Post (Nov. 18, 2010), http://www.huffingtonpost.com/john-e-calfee/when-politics-trumps-scie_b_785094.html.

178. Aim for a Healthy Weight 1, No. 05-5213, U.S. Dep't of Health \& Human Servs. (Aug. 2005), available at http://www.nhlbi.nih.gov/health/public/heart/obesity/aim_hwt.pdf.

179. Calfee, supra note 177.

180. Id.

181. Id.

182. Katherine Hobson, Soda Taxes May Raise Money, Don't Produce Huge Weight Loss, WSJ HEALTH BloG, available at http://blogs.wsj.com/health/2010/12/13/soda-taxes-may-raise-money-don'tproduce-huge-weight-loss/?blog_id=10\&post_id=45173 (Dec. 13, 2010, 16:09 EST). 
response by most to a soda tax would involve altering purchasing behavior but not to the extent of causing people to abandon buying sweetened beverages:

The 1.3-pound weight loss researchers estimate would be produced by such a tax would only likely occur in middle-income households, the study says. High-income households keep on buying soda even when it's more expensive, and low-income ones are more likely to buy generic soda or to purchase in bulk in response to price changes. ${ }^{183}$

Opponents of soda taxes contend that these taxes only do more to hurt poor and more vulnerable populations who are more often engaging in the "bad behaviors" of things like smoking and consuming junk food. ${ }^{184}$ Even if people were to abandon sweetened beverages due to these types of taxes, the untaxed replacements chosen by people could be potentially more harmful to one's health. ${ }^{185}$ When it comes to children, there is even greater concern that simply taxing food and beverage items does nothing to properly educate them about making decisions about eating. ${ }^{186}$ A coalition involving concerned citizens as well as both small and large businesses called Americans Against Food Taxes (AAFT) has emphasized that improper focus is being placed on taxes when it should be on promoting education:

Taxes do not make people healthier. Making smart, educated decisions about diet and exercise do. A new tax will not teach children healthy lifestyles or change their behavior. There is a smarter way to keep our kids healthy, like educating them about diet and exercise. ${ }^{187}$

Another argument is that there are already taxes imposed on soda and junk foods: "While a 'junk food' specific tax is a potential public health intervention, a majority of states already impose sales taxes on certain junk food and soft drinks. ${ }^{188}$ Furthermore, opponents of soda taxes argue that these taxes having nothing to do with combating obesity and are designed merely to raise revenue. ${ }^{189}$ If in fact these taxes are successful and revenue is generated, then the intent of reducing consumption has also likely not

183. Hobson, supra note 182.

184. Andrew Entzminger, Food, Drink Makers Push Back at Soda Taxes, Junk-Food Curbs, WASH. Times (Oct. 13, 2010), available at http://www.washingtontimes.com/news/2010/oct/13/food-drinkmakers-against-soda-tax-junk-food-curbs/?page $=1 \& u t m \_$medium $=$RSS\&utm_source=RSS_Feed.

185. Id.

186. Education Not Taxation, Ams. Against Food TAXes, available at http://www.nofoodtaxes .com/.

187. Id.

188. Chriqui, supra note 63.

189. Calfee, supra note 177. 
occurred because a decline in consumption would produce a minimal gain in revenue. ${ }^{190}$ Others argue that the soda tax proposals thus far have been too minimal and that if such taxes are going to be used, they would have to be greater in order to actually make a difference in people's decisions whether or not to consume these items. ${ }^{191}$

Another argument is raised that unlike the case of tobacco, it is extremely difficult to demonize food when much of it does have some benefits and that there would be difficulty in making distinctions of what food or beverage products should be labeled as "bad stuff" and potentially suffer on the market by a tax. ${ }^{192}$ Finally, a major argument is raised that the government should not become the arbiter of making decisions for people to this extent. ${ }^{193}$ The beverage industry has been a big advocate of suggesting the government is overstepping its regulatory authority and doing so by focusing on the role of parents in being the decision makers for their children. ${ }^{194}$

Colorado recently passed the removal of several exemptions in state sales taxes that included a tax both on candy and soda. ${ }^{195}$ In deciding to implement this tax change, the State had done the following research on the implementation of similar candy and soda taxes across the nation:

A 2006 report from the Grocery Manufacturers Association said 20 other states imposed either a sales tax or special tax on soft drinks and/or candy. Ritter officials say the fact that other states have been doing it shows such a tax could be workable in Colorado despite industry concerns it would be unwieldy. ${ }^{196}$

The definitions of "candy" and "soft drink" under the amendments to the Colorado code apply the sales tax to items that include both sugar and artificial sweeteners. ${ }^{197}$ The definition of "candy" is as follows:

(I) "CANDY" MEANS A PREPARATION OF SUGAR, HONEY, OR OTHER NATURAL OR ARTIFICIAL SWEETENERS IN COMBINATION WITH CHOCOLATE, FRUIT, NUTS, OR OTHER INGREDIENTS OR FLAVORINGS IN THE FORM OF BARS, DROPS, OR PIECES. "CANDY" SHALL NOT INCLUDE

190. Entzminger, supra note 184.

191. Choate, supra note 155.

192. Calfee, supra note 177.

193. Choate, supra note 155.

194. Entzminger, supra note 184.

195. Colo. Rev. Stat. § 39-26-707 (2010).

196. Tim Hoover, Ritter's Plan to Tax Soda and Candy Gets Cheers, Jeers, Denver Post (Nov. 15, 2009), available at $\mathrm{http}: / / \mathrm{www}$. denverpost.com/ci_13791335.

197. Colo. Rev. Stat. §39-26-707. 


\section{ANY PREPARATION CONTAINING FLOUR AND SHALL REQUIRE NO REFRIGERATION. ${ }^{198}$}

"Soft drinks" are defined as follows:

(II) “SOFT DRINKS” MEANS NONALCOHOLIC BEVERAGES THAT CONTAIN NATURAL OR ARTIFICIAL SWEETENERS. "SOFT DRINKS" DO NOT INCLUDE BEVERAGES THAT CONTAIN MILK OR MILK PRODUCTS, SOY, RICE, OR SIMILAR MILK SUBSTITUTES, OR GREATER THAN FIFTY PERCENT OF VEGETABLE OR FRUIT JUICE BY VOLUME. ${ }^{199}$

While the adoption of the removal of the exemption was primarily intended to produce revenue for the State, it was not well-received by members of the food industry who felt that the increase would impact their business: "Eliminating the tax exemptions would bring in an estimated $\$ 3.6$ million according to Ritter's plan, but would result in a 2.9 percent sales tax being restored on candy and soda. As with similar measures in other states, it could burden local candy suppliers and retailers." ${ }^{200}$ The implementation of the tax on candy and soda will also be applicable to the sale of such items in vending machines.$^{201}$ It seems that Colorado will achieve its goal of increasing the State's revenue but more research is accumulating to support the contention that a slim sales tax like this is not enough to have an impact on consumption and therefore, obesity. ${ }^{202}$ It has been suggested that a tax much larger than Colorado's - approximately 18 cents for every $\$ 1$ - would have a "significant difference." ${ }^{203}$ But there are others contending that even a higher tax is not going to be sufficient enough to actually change the patterns of consumption and that the real work must come from people themselves changing their lifestyles to find balance in eating and participation in physical activity. ${ }^{204}$ While many also advocate for such taxes arguing that the use of the revenue can be used for health programs, this is often not what the revenue is used for. ${ }^{205}$ While Colorado's main purpose for implementing the candy and

198. $I d$.

199. Id.

200. Colorado Contemplates Candy Tax, CAndy \& Snack Today (Feb. 3, 2010), available at http://www.candyandsnacktoday.com/archives/2010/02/colorado-contemplates-candy-tax.shtml.

201. Colo. Rev. Stat. § 39-26-707.

202. Mike Stobbe, Colorado Soda Tax: Study Shows Taxes on Soda in Other States Has Little Effect on Consumption, Huffington Post (Apr. 1, 2010), available at http://www.huffingtonpost.com/ 2010/04/01/colorado-soda-tax-study-s_n_521481.html.

203. Stobbe, supra note 202.

204. $I d$.

205. Why Soft Drink Taxes?, CTR. FOR SCI. IN the Pub. INTERest, available at http://www.cspinet 
soda taxes is to raise revenue, there is no indication the state intends to use this money for the purpose of funding such endeavors. The Colorado sales tax on candy and soda has contributed to reigniting the debate on these taxes but does not offer the promise of much movement towards decreasing obesity as a result of these taxes.

What does all of this mean for the proposed Vermont tax? Vermont's proposal does not differ substantially from the other states that have pursued a soda tax except for the distinction it has made between sugar sweetened and artificially sweetened drinks choosing to only tax the former. Many of the arguments by the opponents could ring true for this proposal in particular that the tax (just one cent per ounce) is so slim of a financial burden that it will not prevent people from paying a little more for sweets. While Vermont may also appear to be taking a generous approach by only taxing sugar sweetened beverages and leaving the artificially sweetened beverages alone, the reasoning cited that artificially sweetened beverages do not contribute to obesity could easily be applied to the sweetened beverages with the lack of solid scientific evidence linking sugary sweet drinks to obesity. ${ }^{206}$ Even the studies that have been performed and used to support the contention that a link does exist between sugar sweetened beverages and obesity are not persuasive. ${ }^{207}$

Vermont is attempting to jump on the sweetened beverage-obesity link bandwagon like other states without the evidence to back it up both in terms of the lack of proof scientifically that a link exists and evidence that the minimal additional cost to consumers will really push people away from purchasing these beverages. ${ }^{208}$ While it seems that even the claim that artificially sweetened drinks do not cause obesity is being used by the State of Vermont to at least keep some residents satisfied, the science on this issue is also murky. In fact, some studies have been linking the consumption of artificially sweetened beverages with weight gain including the International Journal of Obesity. ${ }^{209}$

\footnotetext{
.org/liquidcandy/whytax.html.

206. Calfee, supra note 177.

207. Id. (For example, a British study of 644 kids between the ages of 7 and 11 found that the children who drank fewer carbonated beverages had lower BMIs after one year compared with kids who did not. But the difference in BMI was not statistically significant. That means the difference could easily be explained by random chance. This study did find that kids who drank fewer sodas were slightly less likely to become obese.)

208. Kate Daily, Can Laws Fix the Obesity Crisis?, Newsweek (Nov. 16, 2010), available at http://www.newsweek.com/2010/11/16/will-soda-taxes-and-fast-food-bans-fix-obesity.html.

209. Mike Adams, Artificial Sweeteners Like Aspartame and Sucralose May Actually Promote
} 
The focus of this argument here is on the manner in which consumption of artificially sweetened beverages causes people to overeat because a person's body is fooled by the artificial sweetener. ${ }^{210}$ The body believes the person is taking in healthy sweets and that increases appetite. ${ }^{211}$ While it seems that other states that have proposed bans on soda have not taken as divisive an approach as Vermont, the Vermont proposal is no more valiant as it also lacks the serious evidence that sugar sweetened or artificially sweetened drinks do or do not have direct links to obesity. Secondarily, there is little support to suggest that a slim tax of this nature will dramatically impact consumer spending and consumption of these sweet beverages.

\section{Conclusion}

While childhood obesity continues to grow, a number of different avenues have been and continue to be pursued in health law policy to respond to a dilemma that is complicated by the fact that obesity is caused by a number of different factors. The challenges in regulation to combat obesity mirror those in many other areas of health law but particularly with tobacco products. ${ }^{212}$ When dealing with an area that has such a vast industry that is a huge economic source for the country (food/drink manufacturers, tobacco) and the threat of serious health consequences, there has to be some balance to allow for both the flourishing of the industry and the protection of the people's well being.

While there are doubters of the effectiveness of using taxes on soda and other "junk food," their potential value cannot be ignored but to push forward for such measures without the evidence supporting both their link to obesity and their effectiveness is poor public policy. As the desire to examine this approach goes global, it will likely be only a matter of time before there is

Obesity and Weight Gain, Says Research, NaturalNews.com (July 1, 2004), available at http://www.naturalnews.com/001253.html; see also David Ludwig, Artificially Sweetened Beverages: Is It Nice to Fool Mother Nature?, Thrive (Dec. 10, 2009), available at http://childrenshospitalblog .org/artificially-sweetened-beverages-is-it-nice-to-fool-mother-nature.

210. See Adams, supra note 209.

211. Id.

212. See Obesity Epidemic "Deadly" Result of Societal Shifts in the 20th Century, CTR. FOR SCI. IN the Pub. Interest (Mar. 9, 2000), available at http://cspinet.org/new/obesity.html; see also Tobacco Porn: The Faulty Logic Behind the New Cigarette Warnings, CHI. TRIBUNE (Nov. 13, 2010), available at http://articles.chicagotribune.com/2010-11-13/news/ct-edit-smoking-20101113_1_anti-smoking-messagesdangerous-smoking-first-puff; Katherine L. Griem, Voice of the People: Smoking Kills, Chi. Tribune (Nov. 26, 2010), available at http://articles.chicagotribune.com/2010-11-26/news/ct-vp-1126voice lettersbriefs- 20101126_1_warning-labels-youth-smoking-cigarette-packs. 
research to substantiate whether or not these taxes can be effective. ${ }^{213}$ However, these taxes alone cannot attempt to solve the problem and therefore, must be complimented by other legislative measures such as other measures discussed that have been used in attacking childhood obesity thus far and other measures that may not yet have been discovered. Similarly, the challenge of tobacco cannot depend on something like the new textual and graphic warning labels as the only means of addressing the enormity of the health problems there as well as allowing the tobacco industry to prosper and demands creative legislative solutions. ${ }^{214}$

A multi-faceted legislative approach is critical because there is no guarantee that one particular legislative avenue will be effective enough to reach all and can still allow respective industries to survive. ${ }^{215}$ This approach also can help towards balancing the respective interests of industry, the individual, and society that may be useful in tackling many complicated issues in health law. The law itself cannot be the sole contributor in fighting childhood obesity. Even in creating the Let's Move campaign, Michelle Obama recognized the importance of having an approach must involve different disciplines in order to make change, "This problem can't be solved just by passing laws in Washington. It's going to take all of us - governors, mayors, doctors, nurses, businesses, non-profits, educators, parents - to tackle the challenge once and for all, so Let's Move to end the epidemic of childhood obesity together." ${ }^{216}$ For the law to have an impact on childhood obesity, it must address more than simply toughening up on food and beverages and for a multi-faceted approach in the law to be effective, it must be embraced by various disciplines and all the members of a community to put the laws into practice.

213. Christina Frangou, Growing Debate Over Fat Tax, Postmedia News (Mar. 1, 2011), available at http://www.canada.com/health/Topic/Childhood+Obesity/Growing+debate+over/4365189/story.html.

214. See Tobacco Porn, supra note 212; see also Griem, supra note 212.

215. CTR. FOR SCI. IN the Pub. Int., supra note 64.

216. About page, Let's Move!, http://www.letsmove.gov/about (last visited May 13, 2011). 